\section{Espiral de silêncio: uma hipótese para explicar a estratégia de poder do PT no Rio Grande do Sul}

\section{RESUMO}

Este texto discute as estratégias de comunicação do Partido dos Trabalhadores no Rio Grande do Sul à luz da hipótese da "Espiral do silêncio". Tenta-se mostrar que há um descolamento entre um discurso da transparência e uma prática que pode calar oponentes.

\section{ABSTRACT \\ In this text the author examines the communication strategies adopt- ed by the Workes Party in the Rio Grande do Sul from the perspective of the "Spiral of silence" hypothesis. He tries to show there is a signifi- cant difference between its discourse of political transparency and its practice of trying to keep its opponents' mouths sut.}

PALAVRAS-CHAVE

- Comunicação (Comunication)

- Política Partidária (Party politics)

- Filosofia Polítca (Pollitical philosophy)

\section{Introdução}

O Brasil é um país que apresenta um contraste bastante aguçado e original, talvez único no mundo, entre o altíssimo padrão de qualidade de sua televisão - tecnicamente uma das melhores que se produz no mundo (sem entrar no mérito da qualidade dos conteúdos) - e a baixíssima qualidade de sua cidadania, resultante de um longo processo histórico marcado pela desigualdade social, a falta de acesso da população de baixa renda ao conhecimento proporcionado pela educação e o autoritarismo das elites nacionais em relação à sociedade.

O resultado dessa perversa combinação de fatores elevou a televisão brasileira à condição de um vigoroso e influente meio de comunicação social e, ao mesmo tempo, de fabricação e reprodução do poder, historicamente já bastante concentrado em poucas mãos. A relação entre os meios de comunicação de massas e o poder é objeto de estudo tanto da Ciência Política como da Comunicação Social contemporâneas, mas no Brasil a relação entre mídia e poder parece ter alcançado contornos ainda mais evidentes e exacerbados do que em outros países.

Nesse contexto, a campanha eleitoral de Fernando Collor de Mello à presidência da República, em 1989, parece ter, por um lado, contribuído para evidenciar ainda mais essa constatação, e por outro lado, parece também ter inaugurado uma "nova era" no marketing político tal como até então era praticado no país.

O efeito combinado desses dois fatores, isto é, do contraste entre a alta qualidade da nossa televisão e a baixa qualidade da nossa cidadania, por um lado, e por outro, do sucesso da candidatura de Collor de Mello na eleição de 89 - um candidato até então desconhecido da maioria da nação e que ascendeu meteoricamente à presidência da República através de uma bem concebida estratégia de comunicação e marketing eleitoral -, parece ter criado no mercado político brasileiro a falsailusão

\footnotetext{
Paulo Moura

Professor da ULBRA/RS
} 
de que a publicidade eleitoral, especialmente através da TV, tem o poder de substituir a política. Isto é, parece ter se consolidado entre boa parte do sistema político brasileiro a falsa impressão de que um partido ou candidato pode conquistar e preservar o poder conquistado, desprezando as relações reais de poder que se estabelecem entre os diferentes grupos esetores da sociedade, e desses com o Estado, e substituindo seus vínculos sociais concretos pela mera exposição bem "marketizada" da imagem do "príncipe" na mídia.

O apogeu da vigência dessa ilusão ocorreu com a eleição da figura controvertida, emblemática e estigmatizada do senhor Paulo Maluf (PPB) à prefeitura de São Paulo em 1992; consolidou-se com o novo sucesso do publicitário Duda Mendonça, que após a eleição de Maluf, elegeu também o então desconhecido sucessor do ex-prefeito, o senhor Celso Pitta (PSL), e, finalmente, parece ter entrado em decadência a partir das eleições de 1998. Sua participação na campanha presidencial de Lula em 2002 é uma tentativa de voltar à posição de destaque de que desfrutava antes de 1998.

Nesse ano, Duda Mendonça, o até então "mago" do marketing político brasileiro, abraçou, através de sua agência, nada menos do que dezoito campanhas eleitorais simultâneas, entre candidaturas a governos estaduais, ao Senado e à Câmara dos Deputados, em diferentes estados, e fracassou em todas as principais eleições de que participou. Seu erro fundamental parece situar-se na tentativa frustrada de compartilhar custos e maximizar lucros, ao aplicar a mesma fórmula "pasteurizada" e as mesmas soluções publicitárias às diferentes realidades políticas, culturais, sociais e econômicas dos heterogêneos estados brasileiros em que suas equipes trabalhavam, sob sua supervisão, a partir de uma luxuosa estrutura ancorada em São Paulo, de onde o marqueteiro comandou pessoalmente a derrota de Paulo Maluf para Mário Covas, na eleição de 1998.

Toda essa digressão inicial tem por objetivo situar o ângulo de abordagem do tema que é objeto do presente ensaio, cujo objetivo é o de caracterizar o lugar e o papel desempenhado pela comunicação e pela política na estratégia de ascensão ao poder do Partido dos Trabalhadores no Rio Grande do Sul. Isto não só por causa dos motivos antecipados nos parágrafos anteriores, mas também porque é comum a cada área do conhecimento enfocar as diferentes dimensões da realidade sobrevalorizando prismas derivados de seus paradigmas e referenciais teóricos. Dessa forma, psicólogos tendem a "psicologizar" suas análises da realidade; politólogos tendem a politizar suas análises da realidade e comunicólogos tendem a atribuir valor excessivo, e por vezes desproporcional, ao peso e papel da comunicação nos processos sociais e políticos, e assim por diante.

No presente caso, pretende-se trabalhar entre a tênue interface entre a comunicação e a política, para levantar uma hipótese explicativa para a ascensão ao poder do PT no Rio Grande do Sul, a partir de alguns pressupostos da Teoria da Espiral do Silêncio de Noelle-Neumann.

\section{Comunicação interpessoal X mídia}

"Não se confirmavam, assim, a hipótese de que um maior uso da mídia correspondia à maior capacidade de percepção do clima de opinião ou que o maior uso da mídia possibilitasse maior percepção quanto à sua inclusão ou exclusão do grupo da maioria ou minoria de opinião em relação a tal tema. Concluía-se, ao contrário, que a saliência do tema era um previsor muito mais poderoso da expressão de opinião do que o uso da mídia em si. (. . .) a comunicação interpessoal mostrou ter maior capacidade de traduzir a correta percepção do lugar que ocupa o indivíduo em relação à maioria de opinião do que o uso da mídia".

A citação acima refere-se às conclusões a que chegaram os pesquisadores Tony Rimmere Mark Howard ao desenvolverem uma experiência de aplicação da hipótese da espiral do silêncio, com base no conceito de ignorância pluralística ${ }^{2}$, e que, a nosso ver, coincidem com a percepção empírica que origina a hipótese explicativa para a estratégia de chegada ao poder do PT no Rio Grande do Sul aqui apresentada.

Noelle-Neumann desenvolveu sua teoria ao observar séries de pesquisas feitas pelo Instituto Alensbach, sobre a percepção que os alemães tinham de si mesmos, a partir da influência das opiniões que a mídia alemã transmitia sobre essa questão. Com base na constatação da existência de uma relação entre os conteúdos que a mídia veiculava sobre esse tema e o comportamento dos receptores dessas mensagens, a pesquisadora constatou 
a ocorrência do efeito de acumulação sugerido mo hipótese de agenda setting, a partir da qual concluiu que a influência da mídia era bem mais forte do que se poderia imaginar. Segundo sua constatação, "esta influência, ao contrário do que se dissera nas últimas décadas, não se limitava apenas ao sobre o que pensar ou opinar, como afirmava a hipótese de agenda, mas também atingiria o que pensar ou dizer. ${ }^{3} \mathrm{~A}$ partir daí a preocupação de Noelle-Neumann dirigiu-se para a tentativa de entender como se dava essa conexão entre a mídia e a mudança de opinião na sociedade.

Segundo Michael Singletary e Gerald Stone, a pesquisa de Noelle-Neumann "indicou que as pessoas são influenciadas não apenas pelo que as outras dizem, mas pelo que as pessoas imaginam que os outros poderiam dizer. Ela sugeriu que se um indivíduo imagina que sua opinião poderia estar em minoria, ou poderia ser recebida com desdém, essa pessoa estaria menos propensa a expressá-la".

Assim, a pesquisadora concluiu que, "para o indivíduo, o não-isolamento em si mesmo é mais importante que seu não-julgamento. Parece ser esta a condição da vida humana em sociedade: caso contrário, não será concretizada uma integração suficiente". 5 Segundo Antonio Hohlfeldt, para Noelle-Neumann a dúvida sobre a capacidade de julgamento que o indivíduo tem sobre si mesmo funciona como componente aliado ao medo que torna as pessoas vulneráveis à opinião das demais, especialmente no caso de pertencimento a grupos sociais que podem punir aquele que discorda por ele ir além da linha autorizada. ${ }^{6}$ Estudos posteriores de Solomon Asch comprovaram que a maioria das pessoas tende a moldar-se ao pensamento da maioria das pessoas que integram seus círculos de convivência.?

Assim, as pessoas desenvolveram a capacidade de perceber o que ela denomina de clima de opinião, independentemente do que elas mesmas sintam ou pensem sobre determinados assuntos. Dessa forma, ao perceberem ou imaginarem o clima de opinião sobre certos temas, num primeiro momento elas tendem a se calar e, depois, a adaptarem, mesmo que apenas retoricamente, "suas" opiniões ao referido clima de opinião, ou ao que elas imaginam ser o pensamento da maioria. Ao assim agirem, as pessoas tendem a produzir como conseqüência e resultado de seu comportamento aquilo que os americanos costumam chamar de "a profecia que se auto realiza". Isto é, terminam por transformar em pensamento da maioria aquilo que talvez não o fosse na origem, se não existisse esse tipo de comportamento que, como resultado do efeito dessa espiral do silêncio, acaba angariando prestígio e a adesão da maioria. As pesquisas de opinião publicadas, conforme Noelle-Neumann, somam-se a esse processo, na medida em que externalizam e conferem visibilidade e quantificação "concreta" à percepção, antes apenas imaginada, do que sejam essas alegadas maiorias, ou do que seja "a opinião pública".

Para que esse movimento constante e ascensional da espiral do silêncio se viabilize, deve ocorrer o que N. Luhmann ${ }^{9}$ denomina de tematização. Esse conceito foi incorporado a partir da hipótese da agenda setting, e vem a ser a colocação de um determinado tema, elevado a uma condição de importância e urgência, na pauta da atenção do público receptor. Essa pesquisaaventouahipótese dequeos defensores da facção vencedora de opinião são unificados e confidentes, enquanto que os aderentes da facção perdedora estão isolados em suas perspectivas e, eventualmente,resignados (p.9), enquadrando-se num comportamento social que James Bryce caracteriza como fatalismo da multidão. ${ }^{10}$

A hipótese aqui aventada como explicação para o sucesso da estratégia de poder do PT gaúcho guarda coerência com a proposição teórica de Noelle-Neumann, mas incorpora também a contribuição que a ela agregaram Rimmer e Howard, visto atribuirse, no presente caso, papel fundamental à comunicação interpessoal como instrumento original da fabricação de um determinado clima de opinião favorável a esse partido e seu sistema de crenças e valores, na cidade de Porto Alegre, num primeiro momento, e no estado do Rio Grande do Sul, em seguida. No caso, tratase da comunicação interpessoal orientada a partir da organização partidária e de seus líderes de opinião em direção à sociedade civil e seus grupos organizados, e a partir daí em direção aos cidadãos em geral, num processo contínuo desenvolvido ao longo de vinte anos. Não obstante o desgaste provocado pela burocratização da máquina partidária e pela presença no governo estadual, o partido segue investindo nesse tipo de estratégia, sendo o Orçamento Participativo um instrumento-chave para a consecução de seus objetivos. 
Dessaforma, remete-seaumsegundo plano - complementar, mas também fundamental na escala de importância - os diferentes usos que esse partido faz e fez dos diversos instrumentos de comunicação que utiliza, o papel de ferramentas a serviço dessa mesma estratégia de poder. Isto porque, desde as suas origens até muito recentemente, o PT não possuía a quantidade de poder e a influência que detém hoje sobre o Estado e a mídia, para que pudesse agendar os meios de comunicação de massas de forma a desenvolver, a partir deles exclusiva e centralmente, o processo de espiral do silêncio tal como originalmente sugerido por NoelleNeumann.

\section{Um partido como emissor; uma ideologia como mensagem; a conquista da hegemonia como meta}

Para compreender o papel político que o PT cumpriu no desenvolvimento dessa estratégia é preciso, em primeiro lugar, caracterizar bem esse partido e sua cultura política. A tipologia elaborada por Maurice Duverger, adaptada ao caso, parece a mais adequada a essa finalidade. O autor parte de um conceito de partido político segundo o qual ele seria formado por um conjunto de comunidades, uma reunião de pequenos grupos disseminados através do país (seções, comitês, associações locais, etc.), ligados por instituições coordenadoras. ${ }^{11}$

Sua classificação considera a existência de quatro tipos de partidos, quais sejam, o Partido de Comitês, o Partido de Seções, o Partido de Células e o Partido de Milícias. No caso presente, interessa-nos a tipificações do Partido de Seções e do Partido de Células, tais como reproduzidas abaixo:

a) O Partido de Seções apresenta como característica fundamental o apelo às massas, através de métodos de recrutamento e afiliação de membros. Esse tipo de partido buscaria transcender às ações exclusivamente eleitorais, procurando difundir e implantar processos de educação e socialização políticas. Para Duverger, esse tipo de estrutura partidária é ligada à tradição socialista (refere-se aos partidos socialdemocratas europeus da virada do século XIX para o século XX, cuja organização tinha bases regionais correspondentes aos distritos dos sistemas eleitorais desses países) e seu objetivo original seria o de enquadrar as massas, educá-las e criar, no seu seio, lideranças populares eventualmente capacitadas $\mathrm{aO}$ exercício de funções de governo.

b) O Partido de Células corresponderia ao modelo dos partidos comunistas, organizados em termos de grupos de militantes profissionais, geralmente organizados por local de trabalho. Suas estruturas são relativamente menores do que a dos partidos de seção, variando, segundo Duverger, entre 15 e 20 membros, números que coincidem com o de integrantes dos chamados núcleos de base através dos quais originalmente organizava-se o PT.

Por sua inserção em locais de trabalho e associação com vínculos de solidariedade estabelecidos em mobilizações de reivindicação sindical, as estruturas de células tendem a desenvolver padrões de autoridade mais fortes do que no caso dos partidos de seção. Os objetivos desse tipo de organização partidária seriam, fundamentalmente, os de agitação política e propaganda, sendo que no Ocidente em geral atuavam na clandestinidade, e relegando as preocupações parlamentares e eleitorais, em geral vistas como terrenos burgueses de luta política, a um segundo plano.

Um mistura desses dois modelos, guardadas certas características específicas, mais se aproximaria do perfil de atuação, no primeiro caso, e de organização, no segundo caso, idealizado pelos fundadores do Partido dos Trabalhadores na sua fase de formação, nos primeiros anos de sua existência. ${ }^{12}$

Enquanto esteve fora do poder de Estado, o PT desenvolveu uma poderosa estrutura organizativa que atuava junto à sociedade através de núcleos de vinte ou mais militantes, que agiam junto às comunidades, locais de trabalho ou movimentos sociais. Aos poucos, tornou-se o maior partido da esquerda brasileira, controlando a Central única dos Trabalhadores (CUT), principal central sindical do país, o Movimento dos Trabalhadores Sem Terra (MST) - considerado o maior movimento social de massas no mundo hoje -, dentre outras organizações não-governamentais e movimentos sociais existentes no Brasil atual. Progressivamente, foi também galgando postos de Estado em decorrência de um vertiginoso processo de crescimento eleitoral, que o transformou num dos principais partidos do país.

Uma das transformações significativas ocorridas durante o breve processo evolutivo do partido foi detectada por uma pesquisa desenvolvida em 1990, que demonstra, através 
de diversos dados quantitativos, o crescimento da presença de setores de classe média especialmente funcionários públicos -, em detrimento de setores sindicais e populares urbanos e rurais, encontrados em maior número nos seus organismos dirigentes nos primeiros anos de sua existência. ${ }^{13}$

Outro estudo de $1995^{14}$, que analisa o perfil dos integrantes do Partido dos Trabalhadores, conclui que, tomando-se como base a comparação entre o perfil socioeconômico e demográfico da população brasileira e a composição social do partido vista através do mesmo corte, o PT deve ser considerado como um partido de massas, embora não passível de classificação como um partido classista nos moldes tradicionais, pois para isso precisaria apresentar composição majoritariamente integrada por militantes e filiados ligados ao setor secundário ou trabalhadores diretos. Por este critério, então, o PT mais se aproximaria do perfil dos partidos multiclassistas contemporâneos (por acompanhar tendências de modificação da economia em direção ao crescimento do setor terciário em detrimento dos setores primário e secundário). Além disso, revela que o PT se compõe majoritariamente de integrantes de renda média e de escolaridade elevada, assim como de parcela considerável de assalariados rurais e de pequenos proprietários rurais e urbanos.

O bloco social a que pertencem os integrantes do PT compõe-se, portanto, de segmentos integrados ao processo de modernização recente do país, sendo parte de sua força de trabalho e do mercado consumidor, ainda que de forma diferenciada. ${ }^{15}$ Uma análise dos resultados eleitorais alcançados pelo PT em todo o Brasil, e também no Rio Grande do Sul e em Porto Alegre, confirmará a constatação de que o principal contingente de eleitores desse partido também se enquadra nesse perfil socioeconômico e cultural.

Outro elemento constitutivo do PT, digno de registro para fins do presente ensaio, diz respeito à cultura política de sua militância que, conseqüência das características organizativas mistas, ao mesmo tempo inspiradas na tradição dos partidos socialistas europeus e no tipo de organização do antigo Partido Comunista russo (ver nota de rodapé número 17 abaixo), transformou esse partido numa poderosa máquina política de massas, mas com uma cultura de militância extremamente ativa e diferenciada em relação à tradição partidária da política brasileira.

Inicialmente formadas por uma maioria composta de sindicalistas e lideranças comunitárias e de movimentos sociais de origem popular, as estruturas intermediárias do PT foram, gradativamente, sendo tomadas por militantes de classe média, formados pela tradição leninista de militância profissional, herdada dos grupos de esquerda que foram aderindo ao PT ao longo de seu processo de construção. ${ }^{16}$

Esse progressivo avanço da militância das organizações de esquerda - tendências segundo o jargão interno - provocou mais uma transformação no PT. Tratouseda mudança na correlação de forças internas que compõem seus organismos dirigentes, cuja culminância evidenciou-se no Encontro Nacional do partido que antecedeu as eleições presidenciais de 1994, quando os setores caracterizados como esquerda do espectro ideológico interno à legenda tornaram-se maioria pela primeira vez, derrotando Lula e os setores caracterizados pela sua militância como de "centro" e "direita".

Essa transformação, embora só tenha se tornado evidente ao público externo naquele momento, é fruto de um processo de longo prazo que tem origem na adesão ao partido dos vários grupos marxistas-leninistas e trotskistas oriundos das experiências malsucedidas de luta política das esquerdas nas décadas anteriores.

Esses grupos políticos, embora não mais atuem formalmente sob o princípio leninista do centralismo democrático ${ }^{17}$ e nem possam mais - por decisão de um congresso partidário que mudou seus estatutos e regulamentou as tendências - recorrer a organismos próprios paralelos às estruturas oficiais do PT, mantêm vícios característicos da cultura política autoritária leninista, componente que marca sua atuação como correntes internas do PT e que influencia decisivamente as práticas e posições políticas que o partido assume, tanto mais quanto mais influência esses setores exercem sobre as diferentes instâncias partidárias nos vários estados do país.

São traços característicos das práticas desses grupos, entre outras:

a) O dogmatismo ideológico que privilegia estratégias apoiadas na defesa conservadora de posições ortodoxas (alianças eleitorais somente com partidos de esquerda; tratamento de adversários eleitorais como inimigos de classe; 
centralização de poder e controle rígido dos organismos partidários; tentativas de ressuscitar, quando no poder, práticas fracassadas de intervenção do Estado na economia; por exemplo), em detrimento de uma atuação apoiada na consulta às bases e na análise da realidade concreta e sua dinâmica;18

b) O privilégio tático conferido a uma política de acúmulo de forças para uma almejada tomada do poder (pela via revolucionária, se necessário) no futuro;

c) A atuação política nos movimentos sociais, nas instâncias internas do partido e nas instituições e na sociedade, inspirada na teoria leninista da tomada do poder, inclusive por meios não pacíficos e/ou não-institucionais se necessário; e também a rígida disciplina de grupo na luta pela conquista de espaços nos organismos partidários, que muitas vezes leva-os a sacrificar objetivos estratégicos gerais da legenda (deixar de apoiar um candidato moderado bem posicionado nas pesquisas de opinião, em detrimento de um candidato radical numa prévia ou acordo préeleitoral, sacrificando a conquista de apoio de segmentos conservadores da sociedade e a vitória numa eleição, para demarcar posições e fazer propaganda, por exemplo), em nome de objetivos de controle interno sobre as estruturas do partido, sob hegemonia de grupos alinhados com seus pontos de vista ideológicos. Ou seja, tendem a considerar melhor perder a eleição com um candidato de perfil radical, identificado com as posições do "nosso campo", do que vencer a eleição com um candidato "reformista e conciliador".19

No caso específico do Rio Grande do Sul e da cidade de Porto Alegre, esse segmento mais à esquerda do espectro ideológico interno ao PT compõe, através de uma aliança dos grupos mais ortodoxos, a maioria que controla a máquina partidária e comanda o governo do Estado, ao qual o partido chegou nas eleições de 1998.

Aos ingredientes anteriormente referidos, cabe agregar mais um, fundamental para a compreensão da cultura política petista, de seus métodos de atuação e suas estratégias de poder. Trata-se da influência da concepção gramsciana ${ }^{20}$ de estratégia de esquerda para a tomada do poder a partir da conquista da Hegemonia.

$\mathrm{Na}$ cultura política de esquerda, existem pelo menos duas concepções do conceito de
Hegemonia aplicado à relação do partido com a sociedade. A concepção mais vinculada à tradição leninista, e que pode ser encontrada em escritos do próprio Lenin, de Bukharin e de Stalin, aproxima o conceito de Hegemonia mais à noção de coação do que a de persuasão; mais à noção de imposição do poder pelo uso da força do que à capacidade de liderança; mais à condição de submissão política de quem é vítima da Hegemonia de outros do que à noção de legitimação do poder pelo consenso, via processos de longo prazo de construção de influência cultural, intelectual, moral e através da comunicação persuasiva.

$\mathrm{Na}$ cultura política italiana, influenciada pelo legado intelectual de Gramsci, parece prevalecer a concepção de Hegemonia predominantemente entendida como capacidade de direção intelectual e moral, a partir da qual a classe dominante ou aspirante ao domínio consegue se fazer aceita como dirigente legítima dos destinos da sociedade, através da conquista do consenso ou da submissão passiva da maioria da sociedade às metas impostas à vida social e política dessa mesma sociedade.

A "teoria da Hegemonia" ocupa lugar central nas reflexões teóricas de Gramsci sobre a política e o Estado modernos e encontra-se explicitada nos Quaderni del cárcere. Para o autor, a supremacia de uma classe sobre uma determinada sociedade ocorre pelo recurso complementare integrado de formas de domínio e Hegemonia. O domínio se impõe através de mecanismos de coerção típicos da sociedade política, e a Hegemonia é exercida sobre grupos sociais aliados ou neutros (neutralizados talvez?), através de mecanismos hegemônicos típicos da sociedade civil.

Todo Estado, portanto, apóia-se, segundo Gramsci, sobre combinações variáveis, conforme o grau de desenvolvimento de cada sociedade civil, dos fatores força e consenso. Para ele, a sociedade civil é o locus da formação e difusão da Hegemonia, e por isso, é sobre a tentativa de construí-la que deve ser dirigido todo o esforço estratégico do partido. Tratase de um pré-requisito estratégico da classe revolucionária. A força que ambiciona "fazer-se Estado" não assegurará o domínio por longo tempo sem primeiro fazer-se hegemônica no bloco social antagônico ao que está no poder, diz ele. Por isso, são freqüentes nos escritos de Gramsci sobre o conceito de Hegemonia e sua 
operacionalização política expressões como "guerra de posições" e "ocupação gradual das casamatas do campo inimigo" por parte das forças revolucionárias.

Lenin construiu sua teoria da tomada do poder pelo partido revolucionário da classe operária, inspirando-seno processo insurrecional que marcou a Revolução Francesa. Já Gramsci inspira-se na análise dos mecanismos de construção hegemônica da burguesia como classe social ascendente para desenvolver sua teoria da Hegemonia. Para o autor, assim como o parlamentarismo, os partidos liberaldemocráticos e a opinião pública cumpriram a função de instrumentos de informação a serviço dos interesses de classe da burguesia mais avançada, operando de forma combinada com as funções sociais estruturadoras da emergente economia de mercado e da então nova organização do trabalho em padrões fabris, a concepção gramsciana de luta pelo poder vê nos conselhos operários (equivalentes funcionais ao Orçamento Participativo), nos sindicatos e organizações da sociedade civil e no partido revolucionário os instrumentos análogos de luta política do proletariado. Ao partido cabe a tarefa de recrutar e selecionar os "intelectuais orgânicos" aos interesses das forças revolucionárias, organizar sua Hegemonia, e muni-los de uma teoria e de uma estratégia que permitam confrontar e reverter a Hegemonia das classes dominantes. ${ }^{21}$

\section{De Gramsci à moderna teoria da opinião pública}

Segundo Noelle-Neumann, opinião pública é "a conexão - da controvérsia, que alguém é capaz de expressar sem o risco de auto-isolamento que tem duas fontes: os mídia e a observação imediata do meio ambiente, do que as outras pessoas pensam e do que elas expressam em público" (p. 146). ${ }^{22}$

Coerente com o ponto de vista expresso anteriormente, qual seja, o de que a comunicação interpessoal cumpriu papel essencial e preponderante sobre o recurso aos mídia na estratégia de poder do PT, dedicaremos um primeiro esforço à caracterização do que aqui se entende como sendo o processo de fabricação da opinião pública e que, ao nosso ver, corresponde à tecnologia de construção da Hegemonia do PT, inicialmente na cidade de Porto Alegre e, em seguida, no estado do Rio
Grande do Sul. Muito embora, é preciso destacar que no caso do estado esse processo ainda não se consolidou, e encontra-se em disputa no presente momento.

Segundo Candido Monzon Arribas ${ }^{23}$, desde o final da ldade Média até a segunda metade do século XVIII, acontecimentos sociais e políticos começam, aos poucos, a mudar a mentalidade social da época, preparando o surgimento do fenômeno a que a expressão "opinião pública" se refere.

O século XV marca a emergência de uma verdadeira revolução científica que transformou a maneira como a sociedade passou a entender a si mesma e as diferentes dimensões da realidade. Conseqüência da influência que as novas descobertas científicas exercem sobre a mentalidade da época, a razão começa a se libertar da influência da fé religiosa e a ganhar autonomia como forma de explicação das diferentes dimensões da realidade. As esferas social e política da realidade não ficam imunes a essas transformações. O exercício do poder antes era explicado a partir da Doutrina Primitiva da Igreja Católica, que justificava a existência de uma hierarquia natural entre os homens. Segundo essa visão, alguns indivíduos nasciam predestinados, por direito divino e/ou herança consangüínea, a governar, e outros, também por desígnio divino, nasciam e viviam excluídos da política e condenados a serem eternamente governados. O fim do feudalismo traz a extinção de um modo de vida vinculado à agricultura, no qual os indivíduos viviam isolados no campo. Ressurge o fenômeno urbano e a ascensão social da burguesia cria as condições para a efervescência política decorrente da ação revolucionária da nova classe social emergente, num contexto de concentração da população nas cidades. Essa conjunção de fatores faz com que o direito ao exercício dompoder passe a ser explicado por justificativas racionais que substituíssem àquelas de ordem metafísica.

Santo Tomás de Aquino (1225-1274), assistindo ao renascimento das cidades, à intensificação do comércio e, em decorrência disso, à entrada do povo na cena política, muda o enfoque das preocupações teóricas da época, e sob influência dos textos de Aristóteles (função política da cidade para a realização das virtudes humanas) passa a reconhecer que o estudo da política requer o uso da razão e não pode se limitar ao âmbito teológico.

Já no início do século XVI, Nicolau 
Maquiavel, em "O Príncipe", revoluciona o pensamento político de seu tempo separando a ética religiosa da ética política. Com isso, confere autonomia à política, ao desenvolver novas idéias para explicar a comunicação entre governantes e governados, e introduz a ética da razão de Estado para justificar a nova lógica da ação política. O pensador florentino defendia a idéia de que o príncipe precisa do apoio popular para governar, e por isso deve recorrer a uma certa técnica de relacionamento com o povo, técnica essa que precisa ser reformulada constantemente, sempre que as circunstâncias assim o exigirem. Para ele, em suas relações com o povo, o príncipe deve cuidar de sua imagem, da sua reputação, e manipulará a opinião pública para manter-se no poder, sempre que necessário.

$\mathrm{Na}$ época, o movimento da Reforma Protestante também jogara papel importante para impulsionar essas transformações sociais, na medida em que mobilizou as consciências européias, tanto no plano religioso quanto político. As seitas religiosas que dele derivaram foram fundamentais na luta pela conquista de liberdades, na medida em que defendiam a liberdade de culto, a tolerância religiosa (e, por conseqüência, política) e uma nova moral da ação em relação à busca do lucro e da riqueza. Nesse período surgem as primeiras concepções de submissão do rei à lei, os questionamentos à licitude da tirania e a concepção do poder do soberano como emanando da soberania popular e não do direito divino.

A invenção da imprensa por Gutenberg, no século $X V$, será outro marco na história da comunicação humana, que conferirá novo impulso a esse ciclo de transformações sociais e políticas, dando origem ao surgimento da propaganda, das "folhas de notícias", dos panfletos polêmicos, do jornalismo opinativo, da formação das correntes de opinião e, conseqüentemente, da censura. Em seguida, o surgimento do correio dará outro impulso a essas transformações, permitindo a expansão da comunicação das opiniões escritas e impressas por toda a Europa.

Paralelamente, os recém-surgidos cafés e salões de chá vão se consolidando como pontos de encontro e como verdadeiras incubadoras de agitação política na segunda metade do século XVII24. A partir daí, as idéias passam a difundir-se através de diversos meios impressos e de discussões grupais, controvérsias e discursos nos cafés e salões ingleses, franceses e alemães. O público pensante, cada vez mais amplo, reforça-se com a imprensa crítica e independente que começa a surgir na época, e a tornar-se o veículo de comunicação desse público.

Com o absolutismo ilustrado surgem as primeiras teorias democráticas sobre a coisa pública, juntamente com o surgimento, ao longo do século XVIII, de segmentos intelectuais preocupados com assuntos públicos em academias, institutos, laboratórios, clubes, salões, cafés, tornando clara a significação da opinião pública e seu papel na sociedade.

Emergem na cena social, intelectual e política da época os pais do pensamento político moderno. A obra de Thomas Hobbes introduz a noção da consciência que se converte em opinião, a partir da qual os atos de crer, julgar e imaginar se nivelam à esfera do opinar, pertencendo todos eles ao âmbito do privado. Locke fala da Lei da Opinião que se erige em juiz de virtudes e vícios, e que seria algo mais do que a mera opinião; significando a malha informal de crenças populares cujo controle social indireto é mais eficaz que a censura formal sob ameaças de sanções eclesiásticas ou estatais.

Rousseau, em 1750, no "Discurso sobre as ciências e as artes" proferido na Academia de Dijon, além de utilizar pela primeira vez a expressão "opinião pública", denuncia o papel negativo da cultura sobre o homem, afirmando que o novo ser social, aculturado e público, vive dependente de formas e da opinião pública, enfim, da observação dos demais. Para o pensador suíço, no início o homem não se guiava por leis, mas por costumes. Era uma sociedade natural, e a opinião era resultado do contato com os demais. Com a passagem do estado natural para o estado social, o homem separa-se do seu entorno. Surgem as formas de organização, o progresso econômico, aumentam as necessidades e ganha novo significado social a preocupação com as aparências. A opinião primitivamente pública da comunidade torna-se opinião privada dos poderosos que fazem valer seus critérios sobre o conjunto da sociedade. Há, assim, uma permanente traição da coletividade, que se sente afastada de sua vontade e juízo pela imposição de critérios que, não sendo seus, pretendem representá-la no mais espontâneo de sua existência. Segundo Rousseau, opinião pública tem a ver com o estilo da democracia grega com o conjunto de cidadãos reunidos 
em assembléia e votando por aclamação. No Contrato Social, o tema da opinião vem unido ao da vontade geral, ainda que seu sistema pretenda negar a opinião pública; não havendo lugar para os públicos ilustrados que questionam o Estado; a opinião pública seria domínio total do Estado e de seus aparatos ideológicos. ${ }^{25}$

Segundo H. Béjar ${ }^{26}$, a opinião pública perde "o caráter libertador e racional que tinha nos círculos intelectuais e se converte em aclamação constante de um Estado cuja perfeição não se questiona. A crítica dos grupos passa a ser considerada traição e crime. A opinião convertese na própria voz do Estado que se caracteriza por sua extensão em todas as esferas e se faz porta-voz da comunidade, que não conseguiu unir em harmonia política, moral e natural, e por identificar o homem e o cidadão".

Não obstante todas essas referências anteriores ao conceito de opinião pública, são os fisiocratas ("economistas" que procuravam formular leis científicas pretensamente naturais) que podem ser considerados como os primeiros expoentes da doutrina da opinião pública, ao atribuírem ao público ilustrado o papel de compreensão, discussão e exposição das leis naturais frente ao poder do Estado, cujo soberano tem a missão de custodiar a ordem natural. ${ }^{27}$

Esses princípios inspiram as revoluções americana e francesa no século XVIII, consolidando a noção que se tinha da opinião pública como sendo um poder que se contrapõe a uma ordem e a um poder que não correspondia aos desejos do povo. No campo político e social, os povos americano e europeu iniciaram as lutas por independência, liberdades e pelos direitos do homem, resultando daí a constituição dos parlamentos, do sufrágio, da democracia e a luta por igualdades e liberdades, que passam a ser temas de preocupação e debate permanente nos séculos XIX e XX.

Com a Revolução Francesa, triunfa a liberdade de expressão, e a opinião deixa de ser patrimônio dos ilustrados e passa a ser do povo, ainda que se tenha de suportar manipuladores de opinião, conforme se denunciava na Comuna de Paris $^{28}$. Essa é a origem das questões teóricas que darão corpo à noção de soberania popular; da lei como expressão da vontade geral; da defesa dos direitos naturais à liberdade, igualdade, segurança, propriedade, resistência à opressão; à realização de eleições livres para escolha de representantes do povo, e à Declaração dos Direitos do Homem.

Emerge o liberalismo que trata de imporse e dominar as consciências, as instituições, o Estado, a economia, primeiro contra a mentalidade conservadora, e depois, frente às correntes socialistas, marxistas e anarquistas que denunciam os pressupostos teóricos e práticos do liberalismo e da burguesia como classe nas instituições públicas, num processo que se completará na Primeira Guerra Mundial. ${ }^{29}$

Stuart Mill, em 1859, escreve "Sobre a liberdade", defendendo o direito dos cidadãos ou dos grupos de divergir pacificamente e expressar sua divergência sem ser prejudicados por isso, contestando o despotismo político moderno e produzindo repercussão no campo da opinião pública e dos conflitos trabalhistas no que diz respeito ao direito de greve, às manifestações de fé religiosa e à publicação de idéias políticas. Os escritos de Tocqueville caminham na mesma direção, e o debate sobre a ampliação do sufrágio faz com que a opinião pública apareça dividida, convertendo a opinião pública dominante em um poder coercitivo. Ambos reconhecem a opinião como uma força que pode servir para limitar o poder. ${ }^{30}$

Segundo o liberalismo, o ponto de partida encontra-se na esfera privada da sociedade civil, formada por pessoas que têm interesses, problemas e opiniões particulares. No âmbito privado, o homem guia-se por leis naturais e defende os direitos naturais, cabendo aos indivíduos, segundo seus dons, dentro da iniciativa privada e da competição, conseguir suas aspirações humanas. De outro lado está a esfera pública; o poder público, o Estado, que, através dos governantes e da administração, trata de regular os assuntos de interesse geral. Há, portanto, duas esferas, a privada e a pública, que correspondem à ordem social e a ordem política. $\mathrm{O}$ homem pertence à sociedade civil e como cidadão participa da vida pública.

Em teoria, os liberais admitiam a autonomia da esfera privada sobre a pública, mas interesses comuns e uma agressividade própria do Estado impediriam tal autonomia. Como resposta, o cidadão se interessa pelo que é público e busca formas de controlar o poder a sua atuação. A comunicação política entre governantes e governados se faz necessária e os acontecimentos que ocorrem a partir da Revolução Francesa são o melhor exemplo de tais relações. Com a revolução, a burguesia ascende ao poder, situação que a impede de se 
opor ao Estado democrático. A opinião pública, de certo modo, se canaliza e se converte no parlamento, que passa a ser o lugar onde se passa a ouvir sua voz através dos representantes do povo. No entanto, quando os liberais falam de opinião pública, referem-se àquele público que pensa como personalidades privadas sobre assuntos públicos, mantendo uma atitude crítica frente ao poder, agora democrático e constitucional. ${ }^{31}$

Mas, inquire Arribas, "quem é esse público? São todos os cidadãos? Pode-se dizer que público é todo o mundo, ou deve-se limitar a um grupo reduzido que, por gozar de privilégios, são de fato do raciocínio público? -os liberais referemse aos interesses da burguesia (os proprietários e ilustrados), obviamente, e inclusive colocavam obstáculos para que o povo ocupe espaços civis e políticos; e ainda exigem que se articulem os meios para que sejam educados e informados sobre os assuntos públicos, a educação pública transforma-se em direito e dever; e a imprensa se converte em mediadora entre os cidadãos e o Estado. ${ }^{32}$

Suposta a existência de um público interessado nos assuntos de interesse geral, e suposta a informação, o debate; o contraste de opiniões será o passo seguinte até chegarse ao consenso. Os liberais partem do princípio de que ninguém detém o monopólio da verdade e que só o diálogo e o debate público levam os cidadãos ao conhecimento e à solução dos problemas públicos. Teoricamente todos os homens adultos eram cidadãos, mas na realidade somente os proprietários o eram. A opinião pública, portanto, restringia-se àquele grupo de pessoas privadas que podiam exercer o raciocínio sobre os assuntos públicos, ou seja, restringia-se à classe dominante..$^{33}$

Monzon Arribas sintetiza em seis tópicos básicos o que ele define a articulação da opinião pública segundo a ótica liberal. ${ }^{34}$

10 Uma sociedade civil com dinâmica própria, formada por um conjunto de cidadãos que procuram seus interesses pessoais, constitui a esfera privada.

$2^{\circ}$ Um Estado que administra os assuntos de interesse geral, a coisa pública, e que deve intervir o menos possível na esfera privada, constitui a esfera pública.

$3^{\circ}$ Um público, formado por aquelas pessoas da sociedade civil que se interessam pelos assuntos públicos, o poder e sua situação. Esse público é formado, principalmente, por proprietários, burgueses e ilustrados.

$4^{\circ}$ Este público demanda os meios necessários para fazer ouvir sua voz perante o poder e a sociedade. Entre os meios que considera fundamentais se encontram a educação, a informação e a articulação da vida pública, aspectos que tornam possível a comunicação política.

$5^{\circ}$ Pressupostos os fatores anteriores, o debate será possível, em primeiro lugar, no Parlamento, em segundo lugar, através do raciocínio público que exercem as pessoas privadas sobre os assuntos de interesse geral.

$6^{\circ}$ Esta segunda forma é o que os liberais chamam propriamente de opinião pública. Constitui e se manifesta como uma força moral e crítica sobre a sociedade, o bem público, o Parlamento e o poder em geral.

Segundo o autor, o marxismo critica e tenta desmascarar a postura liberal, afirmando que não existe uma opinião pública, mas tantas opiniões quantas são as classes sociais e o que normalmente se entende por opinião pública não é outra coisa que não a opinião da classe dominante.

O marxismo não explicita essa crítica diretamente, mas ela pode ser depreendida da explicação marxista clássica sobre a estrutura social, os tipos de sociedade, a teoria do reflexo e os conceitos de ideologia como falsa consciência ou alienação, segundo os preceitos do materialismo histórico e dialético. $\mathrm{Na}$ concepção marxista, a ideologia não é apenas a inversão refletida da realidade ou ilusão, mas também é uma força que utiliza a classe dominante para dominar e impor a crença da legitimidade de seu domínio. As idéias e valores da classe dominante são assimilados pelas massas populares da classe antagônica, e sua força é tal que, ainda que desapareçam as condições objetivas que lhes dão sustentação, seguem vivos na mente das pessoas. ${ }^{35}$

A crítica marxista da opinião pública ganhou leituras modernas, especialmente no que diz respeito ao papel dos meios de comunicação de massas e das pesquisas de opinião publicadas pela mídia. Pierre Bourdieu36 e Patrick Champagne $^{37}$ destacam-se no desenvolvimento dessa nova visão crítica do conceito de opinião 
pública na sociedade contemporânea.

Para Bourdieu, a opinião pública no sentido que é conferido a esse conceito pelas pesquisas de opinião publicadas pela mídia não existe; é apenas mais um dos instrumentos de manipulação política a serviço dos interesses dominantes. Para o autor, o que importa é a opinião mobilizada, as opiniões constituídas em grupos, em torno de um sistema de interesses. Opinião consiste, nas palavras de Platão reproduzidas por Bourdieu na epígrafe de seu artigo A opinião pública não existe, em "explicitar posições em um discurso pronunciado", o que pressupõe a capacidade de elaboração de um raciocínio analítico sofisticado, muito diferente daquilo que ocorre com o indivíduo estimulado a responder enquetes de opinião.

Segundo essa visão crítica do conceito, o jogo político se reorganizou e se reestruturou na sociedade contemporânea, em função dos meios de comunicação e das pesquisas de opinião. A política virou espetáculo. Um espetáculo no qual o cidadão virou público espectador, estimulado a aplaudir ou a vaiar os atores políticos. É nesse contexto que o território da política, antes espaço privilegiado e exclusivo dos políticos, vem sendo gradativamente invadido por novos personagens.

Neo-sofistas, publicitários, comunicadores, profissionais de marketing, spin doctors (expressão da língua inglesa que designa o agente político cuja função, atuando a serviço de governos e/ou políticos, é fabricar fatos e fazer prevalecer versões através da manipulação da mídia); e por fim, cientistas políticos que, cumprindo as funções de analistas simbólicos, interpretam comportamentos e expectativas políticas e eleitorais das massas e concebem estratégias para influenciá-las, transformaramse em protagonistas de bastidores, às vezes mais influentes que os próprios políticos, hoje, melhor definidos; atores políticos.

Fazer política, conquistar poder, não consistem mais emaglutinar massas em partidos e grandes mobilizações de rua, cujo destino seria a praça em frente ao palácio do governo, ou mesmo a conquista (às vezes pela força) do próprio palácio. Fazer política na sociedade da mídia eletrônica consiste em fabricar e veicular imagens, fatos e versões, destinados a persuadir e influenciar o comportamento do público espectador, e a estimulá-lo a reagir favoravelmente aos interesses do agente político emissor. Conquista poder aquele que, com mais competência, souber vencer a guerra de imagens, criando ou manipulando fatos e versões e fazendo-os prevalecer, nos espaços privilegiados da mídia, como "a verdade". Transformar um fato ou sua versão em "verdade" muitas vezes é algo que ocorre pela capacidade de um agente político de divulgar seu ponto de vista sobre a interpretação desse fato, mediante a execução de uma eficaz estratégia de divulgação, orientada à ocupação de espaços nos meios de comunicação segmentados e de massas.

É sob a influência dessas circunstâncias que as pesquisas de opinião adquiriram proeminência no tabuleiro da política midiatizada. Mais do que isto, as pesquisas transformaram-se em instrumento fundamental para o jogo do poder. Nesse contexto, os resultados de pesquisas de opinião eleitorais ou de avaliação de desempenho de governos passaram a cumprir um duplo papel. Por um lado servem, aos atores políticos e aos espectadores, como "placar" medidor de força política, entendida como capacidade de influenciar a opinião pública. Por outro lado, formuladas que são por agentes políticos de alguma forma interessados nos seus resultados, elaboradas e tornadas públicas no momento e da forma que melhor interessa ao agente político que as patrocinou, ao serem publicadas pelos meios de comunicação servem também como instrumento de manipulação da opinião pública, a serviço, portanto, de interesses que agem direta e/ou indiretamente sobre o tabuleiro das disputas por poder. Constituem-se em novo ingrediente da comunicação persuasiva e do conjunto de instrumentos de regulação social da sociedade pós-industrial.

Dessa forma, segundo Patrick Champagne, os agentes políticos que pretendem jogar o novo jogo do poder da sociedade midiatizada em que as pesquisas de opinião exercem o papel anteriormente descrito precisam se articular a agir como "autores da opinião pública" através de formas modernas, visto que a luta política tende a se reduzir mais e mais a uma batalha pela conquista da opinião pública medida de forma aparentemente científica e indiscutível pelos institutos de opinião.

Bourdieu mostra, no artigo $A$ opinião pública não existe (ver nota $n^{\circ} 27$ ), que as pesquisas de opinião, ao proporem uma mesma questão para inúmeros indivíduos socialmente heterogêneos, interrogados em função de 
demandas políticas, fazem parecer que todos os indivíduos possuem uma única opinião e que se colocam sempre diante das mesmas questões, e ainda que, desde um ponto de vista social, todas as opiniões se equivalem. $\mathrm{O}$ autor procura comprovar, assim, que os institutos de opinião não medem verdadeiramente a opinião pública, mas sim constroem artefatos valendo-se de um exercício ilegítimo da ciência e esquecendo-se da existência de outra "opinião pública" situada além dos grupos de pressão dos "lobbies".

Com isso, Bourdieu propõe uma verdadeira teoria sociológica sobre a produção da opinião. Em dois artigos posteriores (1976/77), a partir de análises secundárias de diversas enquetes realizadas pelos próprios institutos de pesquisa, ele demonstrou que a probabilidade de haver uma opinião dita "pessoal" varia segundo os grupos sociais, especialmente segundo a formação cultural e, sobretudo, que a competência para responder a uma questão política é técnica e socialmente inseparável como bem se vê pelos índices "políticos" de "não-respostas", ocasionadas por diversos motivos, desde o fato de que alguém possa não se reconhecer no direito de opinar sobre algo, até a possibilidade de não ter interesse sobre a questão.

Segundo o autor, o contexto em que os indivíduos formam opinião sobre campos temáticos de seu interesse "natural" é completamente diferente das circunstâncias que the são impostas pelas técnicas homogeneizantes das enquetes.

Em colaboração com Luc Boltanski, Bourdieu analisou a contribuição da "ciência política" com respeito à "produção da ideologia dominante", demonstrando que a essência da dominação política é de ordem simbólica. A ação política, assim, baseia-se na imposição de um sistema de classificação do mundo social que, embora não sendo verdadeiro, alguém dotado do poder e da propriedade específica de manipular meios simbolicamente eficientes faz parecer verdade, à medida que são trabalhados esses meios, anunciando como desejável o que se pretende que venha a acontecer.

Essa constatação, segundo o ponto de vista aqui explicitado, remete a uma sociologia dos usos políticos de uma prática que tem por característica principal apresentar todos os signos exteriores como científicos, o que, segundo Champagne, requer um esforço em direção à compreensão do sucesso das pesquisas de opinião entre os jornalistas e especialistas da "ciência política" e, até mesmo, por que esta tecnologia social é transportada para a lógica do campo político, ainda que suas origens não estejam relacionadas à "mediatização do campo político", assim como a TV. Para o autor, assim como a fotografia - que veio a responder uma necessidade socialmente preexistente de representação realista -, o sucesso destas técnicas é explicado pelo fato de que elas permitem pôr em prática, com as garantias da aparente cientificidade, uma forma moderna de "democracia direta" como uma complementação da lógica democrática, expressão onipresente e inacessível da ideologia democrática.

Este processo exige, portanto, o redirecionamento do foco da análise, menos sobre as pesquisas de opinião e mais em direção à nova lógica do funcionamento mesmo do campo político. Este, por sua vez, impõe sua força sobre o campo social específico e relativamente autônomo da conquista dos postos de poder sobre a administração do Estado, pela via da mobilização eleitoral de uma maioria de cidadãos em torno de uma mesma representação do mundo social.

Segundo Norbert Elias, a luta no interior dos campos políticos nacionais, que são cada vez mais morfológica e geograficamente vastas, tendem a ser de natureza essencialmente simbólica, pois esta luta se faz com as palavras e visando a fazer crer ou fazer ver, de maneira que a história do espaço político consiste, em grande parte, em analisar as diversas formas desse poder simbólico particular e cada vez mais autônomo. ${ }^{38}$

Assim, a luta, nos debates político-eleitorais, por exemplo, passa a ser a luta pela última palavra. Os profissionais da política tentam, por todos os meios disponíveis e admissíveis nesse espaço de jogo, impor o maior número de pontos de vista, ou ainda, procuram por esses meios apropriar-se da visão do mundo social que eles crêem ser a da maioria dos cidadãos. Os confrontos na mídia moderna (rádio e TV) são saturados de índices que manifestam as preocupações dos jornalistas de ser ou aparecer árbitros imparciais desta luta verbal.

A heterogeneidade política e social da audiência dos meios de comunicação de massa nacionais obriga os jornalistas a convocar representantes de todas as tendências e também, cada vez mais, aos especialistas em 
Para esse autor, a análise de Durkheim ou de Cassier sobre a construção social da realidade pela matriz dos sistemas simbólicos, e especialmente dos sistemas classificatórios, é especialmente válida em política. A ordem política é um efeito da abordagem de uma ordem mental e as estruturas políticas existem em grande parte sobre a forma de representações sociais incorporadas em cada agente social, como bem se pode ver nas situações de mudança política radical. A instauração do voto "democrático" em países autoritários, por exemplo, mostra que a questão não se reduz ao dispositivo material que o organiza (urna, pluralidade de cédulas, cabines indevassáveis), mas implica correlativamente uma verdadeira aculturação política da população. ${ }^{39}$

A livre concorrência política que caracteriza os regimes de tipo democrático tende a ocultar o trabalho de imposição que existe nesses regimes também, e que tem por objetivo criar um consenso sobre os sujeitos de possíveis desacordos. Nos regimes autoritários, esses esforços por tentar impor uma só visão de mundo se tornam mais evidentes. Esses regimes botam, geralmente, toda a sua atenção e energia sobre a socialização política precoce das novas gerações. Enquadrando-se prioritariamente os movimentos de juventude fortemente politizados, porque eles procuram criar uma verdadeira crença política, ou pelo menos um sentimento de evidência e de aceitação, que é precisamente induzido pela existência de estruturas de percepção política e social idênticas no interior de uma mesma sociedade, ou seja, de princípios de visão e de divisão universalmente distribuídos.

Por isso, segundo Champagne, as maiores crises políticas atuais são crises de opinião. As mudanças recentes que emergiram na URSS, e mais geralmente nos países do Leste Europeu, são sobretudo mudanças de visão, por uma grande parte dos çidadãos, da realidade política de seus países. É chocante, diz ele, observar que a maioria dos intelectuais e autoridades soviéticas declara que as transformações em curso eram "impensáveis", ao passo que ao responsável cultural parecia "normal" e "natural" há dez anos selecionar jovens artistas e seus trabalhos para uma exposição, em colaboração com a KGB. As reformas impulsionadas por Gorbatchev foram recebidas com ceticismo, porque foram percebidas a partir de estruturas mentais anteriormente constituídas.
O desmoronamento brutal dos regimes comunistas da Europa do Leste decorre, então, daquilo que Champagne define como desmoronamento de uma crença, mantidos que eram por sua capacidade de imposição pela força. Este desmoronamento seria análogo ao das práticas religiosas antigas nas zonas rurais, que se acelerou com o afastamento da agricultura por parte dos filhos dos agricultores. Este processo constitui uma mediação ou um elo indispensável para a compreensão dos mecanismos de dominação simbólicos, que apelam à "moral" de um grupo social constituinte da expressão subjetiva da interiorização de estruturas sociais objetivas. Como os agricultores que não podem mais se reproduzir socialmente e biologicamente por não conseguirem mais reproduzir a crença coletiva no valor da agricultura tradicional e no modo de vida que lhe é condizente, os regimes políticos da Europa do Leste não conseguiram perdurar porque eles não reuniam mais a capacidade de reproduzir a crença no seu valor como sistema político.40

Uma das maiores diferenças entre os regimes políticos autoritários e os democráticos pode bem residir, portanto, na forma de empreender esta luta simbólica pelo poder. Nas democracias ocidentais a luta se inscreve na lógica do mercado e da concorrência aberta e pública. O capital político específico que os homens políticos devem acumular, individual e coletivamente, é um capital simbólico formado pelo crédito de confiança que o cidadão/eleitor Ihe confere, ou seja, uma combinação variável de crença em sua competência e moralidade. O valor desse capital, que pode ser brutalmente afetado pela revelação de um "escândalo" na imprensa, expediente cada vez mais usado na guerra por poder entre políticos adversários, é permanentemente medido nas múltiplas eleições, mas também pelas manifestações de protesto público e, mais recentemente, pelas pesquisas de opinião.

Os regimes autoritários praticam mais voluntariamente a manutenção da credibilidade política, o sistema de curso forçado e de sustentação assistida pelo aparelho e Estado. A adesão da população a esses regimes que se dizem "populares" é inteiramente produzida por um trabalho político visando, pela via da denegação, a fazer crer a todos, e em primeiro lugar talvez aos próprios dirigentes, que existe sustentação popular.

O que se observa, então, destaca 
Champagne, é que o processo de "democratização" política é cada vez mais marcado pela autonomização do campo político e por sua crescente diferenciação interna, ou seja, pelo surgimento e desenvolvimento de subcampos de agentes sociais relativamente autônomos - jornalistas políticos, politólogos, pesquisadores, especialistas em comunicação, etc. - que, cada um a sua vez e com seus interesses próprios e apostas específicas, participam mais ou menos diretamente o jogo político.

Dessa forma, o jogo político se tornará incompreensível para quem não perceber essa difusão de subprodutos das ciências sociais e o fato de que os atores políticos se cercam de conselheiros em comunicação política formados em técnicas publicitárias, e, sobretudo, para quem não levar em conta as numerosas enquetes publicadas ou não, que são feitas permanentemente para medir o "impacto de uma audiência de TV" ou de uma "campanha publicitária", para prever resultados possíveis de uma eleição a partir de enquetes sobre "intenção de voto" ou sobre a "popularidade" dos principais líderes políticos, ou ainda para testar um "produto" eleitoral (programa eleitoral, tema de campanha) antes de lançá-lo.

Em realidade, reafirma Champagne, repetindo Bourdieu, a "opinião pública" não existe, nem mesmo "a opinião medida pelas pesquisas de opinião", mas sim existe um novo espaço social dominado por esse conjunto de agentes - institutos de pesquisa, politólogos, conselheiros de comunicação e marketing político, jornalistas - que utilizam as tecnologias modernas como as pesquisas de opinião e os meios de comunicação, conferindo, por aí, existência política autônoma a uma "opinião pública" que eles mesmos fabricaram, como profissionais da análise e da manipulação, transformando, da mesma forma, a atividade política tal como se vê na TV e tal como é vivida pelos próprios políticos. ${ }^{41}$

Assim, a mudança da definição da política tende a inverter as formas tradicionalmente estabelecidas de capital político na fase anterior à era do marketing na política. A legitimidade das lideranças e das organizações políticas antes se media pela autoridade acumulada nos partidos mediante a capacidade de recrutar e mobilizar multidões; à arte da eloqüência retórica nas assembléias parlamentares ou nas reuniões partidárias e sindicais, etc., agora é medida por índices em pesquisas de opinião publicadas, sob as circunstâncias anteriormente descritas. Dessa forma, essa mudança pode ser compreendida como uma mudança do próprio campo social, onde os jovens atores sociais sem capital político e não engajados tentam reverter as regras tacitamente aceitas e interiorizadas pela regulação da competição política.

Champagne, fazendo referência a pesquisas sobre o comportamento do eleitorado francês, observa que a quantidade de pessoas que se dizem "muito" interessadas pela política mantém-se estável desde os anos 50 e gira em torno dos 10\% a 14\%.42 Por outro lado, observa uma diminuição regular e importante da maioria dos excluídos e despossuídos que se dizem "nada" interessados em política, sendo que a proporção cai de $40 \%$ nos anos 50, para 20\% em 1984. Aumenta notadamente, também, com o crescimento da escolarização a quantidade de pessoas capazes de exercer um "olhar oblíquo" sobre a política, mais exatamente sobre aquelas a quem a mídia atinge.

Através de um processo circular freqüente em política, pode-se inventar interesse por determinada política, pois os responsáveis pela grande mídia, através da lógica das audiências máximas com que trabalham, procuram explicitamente conduzir ointeresse do olhar pelas emissões que eles fabricam sobre a política, pois segundo a sua definição, a política na definição tradicional não interessa. Assim, a "competência política" adquirida pela maioria do público é do espectador e situa-se na mesma ordem que a da minoria ativa que fala e "faz" a política. De fato, os comportamentos e os discursos dos agentes sociais devem ser restituídos como produtos das estruturas mentais através das quais a política é percebida e que estão longe de ser idênticas às dos politólogos.

Votar em um partido político não significa necessariamente dar-lhe sustentação na forma como ele se define no espaço político, mas sim que uma certa visão da política e da posição dos diferentes atores conduziu à escolha dessa legenda na cédula de votação. Da mesma forma, afirma Champagne, não se pode dizer, após uma enquete, como fazem classicamente os politólogos, que tal ou qual fração da população é de esquerda ou de direita. Seria pretender que essas categorias fossem imediatamente compreensíveis por todos, ou como se o seu conteúdo fosse unívoco e universalmente conhecido e reconhecido. O objeto científico 
da ciência social crítica contemporânea, portanto, reside, segundo esses pontos de vista, precisamente na análise dessas categorias utilizadas em política, isto é, na luta simbólica que joga cada ator político (emissores) e nas diversas significações que Ihes são dadas pelos diferentes grupos sociais (receptores/reemissores) ${ }^{43}$

\section{Da moderna teoria da opinião pública a Gramsci: o jogo do PT}

Nos tópicos anteriores do presente ensaio acreditamos ter sintetizado os ingredientes teóricos capazes de corroborar para a confirmação da hipótese aqui aventada como possível explicação para a bem-sucedida estratégia de poder do PT no Rio Grande do Sul.

De forma geral e esquemática, portanto, seriam os seguintes os vetores do sucesso da estratégia de poder do PT em Porto Alegre e no Rio Grande do Sul:

a) A organização de um partido unindo a experiência da tradição de inserção por base regional dos velhos partidos socialistas europeus, mas também fortemente influenciado pela tradição da militância profissional de inspiração leninista (células militantes inseridas em sindicatos; movimentos sociais e organizações comunitárias, atuando diariamente coladas na base da sociedade organizada);

b) A adoção, ainda que de forma ambígua e não explicitada, por esse partido, das concepções de estratégia gramsciana de chegada ao poder pela via da conquista gradual da Hegemonia sobre a sociedade, conforme explicitada anteriormente;

c) A incorporação ao arsenal retórico desse partido, como se seu monopólio fosse, de um conjunto de valores universais positivos e socialmente aceitos como consensuais, tais como a identificação com a defesa incondicional da justiça social; com a defesa da ética na política e a prática da austeridade administrativa a partir de uma alegada e inquestionável idoneidade moral; e, igualmente, a atribuição de valores negativos e opostos a esses anteriormente explicitados a todos os seus adversários no sistema político e na sociedade;

d) A adoção combinada, a partir dessa estratégia de conquista da Hegemonia, de métodos modernos de formação e conquista da opinião pública, combinados aos tradicionais métodos de luta político-partidária das esquerdas. O PT incorporando, em suas práticas, elementos da visão liberal; marxista clássica e contemporânea, do conceito de opinião pública, tendo como base elementos teóricos aqui explicitados a partir da síntese teórica de Monzon Arribas, Bourdieu e Patrick Champagne, e finalmente também, em função da eficácia na aplicação desses métodos e dessa estratégia, conseguiu desenvolver, na cidade de Porto Alegre (e pode desenvolver no estado do Rio Grande do Sul), um processo de espiral do silêncio tal como sugerida como hipótese atualizada pelos estudos de Rimmer e Howard da teoria de opinião pública de NoelleNeumann.

Tomando por base os ingredientes teóricos anteriormente descritos, seriam os seguintes os vetores teóricos que orientaram a estratégia de poder do PT:

a) A sociedade civil é entendida como possuindo dinâmica própria e sendo formada por um conjunto de cidadãos que procuram seus interesses pessoais, constituindo esta a esfera privada da sociedade.

Como o poder público interfere nas circunstâncias que influenciam a vida privada dos cidadãos, estes agem, de forma individual e/ou coletiva, para reagir a essa interferência. O partido, então, atua no ambiente social, procurando conquistar para seu campo ideológico os cidadãos integrantes dos segmentos médios da população com bom grau de instrução e razoável nível de renda (intelectuais, produtores culturais, jornalistas, professores, artistas, entre outros líderes de opinião), a partir dos quais multiplica e irradia seu potencial de influência social e política para outros segmentos da sociedade;

b) O Estado, sob comando do partido, é entendido como a entidade à qual cabe administrar os assuntos de interesse geral da sociedade, a coisa pública, inclusive intervindo na esfera privada sempre que necessário e que o "interesse coletivo" assim o demandar, trazendo para o debate político na esfera pública temas que seus critérios ideológicos definem como de interesse "da sociedade";

c) Seu público-alvo inicial é formado por aquelas pessoas da sociedade civil que se interessam pelos assuntos públicos, o poderesua situação. Esse públicoéformado, principalmente, por segmentos médios e intelectualizados da sociedade, notadamente por funcionários públicos, os quais o partido estimula a participar 
do debate político em espaços públicos formais e informais, através do que constitui uma poderosa rede de fabricação social de opinião pública e de resistência e enfrentamento político às opiniões divergentes da sua, emitidas a partir do sistema político, cultural, social ou da mídia. Incorporam-se a esses métodos de "marketing direto" (abordagem direta dos cidadãos/eleitores por militantes partidários, eventos políticos e culturais, distribuição de literatura e propaganda partidária e ideológica de produção própria, etc.), a partir da concepção de Bourdieu sobre a opinião pública - para quem o que importa é a opinião mobilizada, as opiniões constituídas em grupos, em torno de um sistema de interesses -, os métodos contemporâneos de luta simbólica através da ocupação de espaços nos meios de massa (cooptação política de profissionais de comunicação), via uso de espaços legais na mídia formal para a propaganda partidária; a participação de seus membros e simpatizantes em debates públicos nos meios de comunicação; o uso de instrumentos alternativos de comunicação impressa e audiovisual;

d) Exatamente como explicitado por MonzonArribas, no item $4^{\circ}$ de sua síntese da visão liberal da opinião pública, este público demanda os meios necessários para fazer ouvir sua voz perante o poder e a sociedade. Entre os meios que considera fundamentais para fabricação e reprodução de sua ideologia, destacam-se o sistema educacional - inicialmente através da cooptação sindical e partidária dos professores, e depois de conquistado o Estado, através da ideologização dos conteúdos programáticos adotados em sala de aula -; a informação e a articulação da vida pública a partir da participação de seus militantes e simpatizantes no debate político formal e informalmente realizado na sociedade e na mídia, seja através da criação de espaços formais novos, como é o caso do Orçamento Participativo, seja através da simples discussão informal de idéias sobre assuntos vários, que tende a acontecer naturalmente nos ambientes sociais das classes médias; ${ }^{38}$

e) Pressupostos os fatores anteriores, o PT inverte a lógica liberal, fazendo primeiro o debate político junto com a sociedade, a partir de seus segmentos organizados e intelectualizados através do raciocínio público que exercem as pessoas privadas sobre os assuntos de interesse geral -, e a partir das organizações sociais, políticas e culturais que controla, e somente posteriormente leva o debate ao parlamento, e aos demais organismos do Estado, os quais pressiona para que atendam a suas demandas, se não detém o poder de controle sobre eles; ou, então, os quais manipula a serviço de seus interesses políticos e perspectivas de poder, quando tem sob seu controle fatias do poder de Estado ou do parlamento;

f) Reproduz-se, dessa forma, o mecanismo da espiral do silêncio proposto por NoelleNeumann, constituindo o que os liberais chamam propriamente de opinião pública, que se manifesta como uma força moral e crítica sobre a sociedade, o bom público, o parlamento e o poder em geral. Conquistado o poder, o PT alia a esses métodos e mecanismos o uso do aparato do Estado e das instrumentalidades disponíveis aos governantes como ferramentas auxiliares desse processo de construção de Hegemonia, sem nunca descuidar do enraizamento da organização partidária na sociedade.

Aplicando toda essa tecnologia aos seus métodos de luta política, o PT gaúcho construiu uma poderosa máquina partidária, infinitamente superior às organizações políticas que lhe são adversárias, em termos de poder de mobilização social e de fabricação de opinião pública, obtendo como resultado, primeiramente em Porto Alegre - onde o processo de sua Hegemonia está consolidado - , e em seguida no estado do Rio Grande do Sul-onde a conquista da Hegemonia pelo PT ainda está em disputa, mas já reproduz as mesmas tendências de constituição de uma verdadeira espiral do silêncio -, a conquista do poder de Estado. ${ }^{39}$

A eleição de 2002 para o governo do Estado do Rio Grande do Sul constitui-se num marco de referência capaz de indicar se essa máquina partidária que o PT construiu, e a penetração que conquistou na sociedade, serão capazes de compensar o medíocre desempenho administrativo do partido, permitindo a reeleição de sua proposta.

Não obstante, mesmo podendo perder a eleição, o que é impossível antecipar no momento em a redação desse artigo é concluída, a candidatura petista apresenta forte competitividade, ainda que enfrentando as adversidades decorrentes do ônus de ter de defender um governo de desempenho regular aos olhos da opinião pública. Certamente estará no segundo turno, e as projeções indicam crescimento significativo de sua bancada legislativa estadual e federal, o que, por si só, corrobora a análise aqui explicitada. A eventual 
derrota do PT nesta eleição pode ser mero acidente de percurso. Fruto de sua estratégia de poder, esse partido seguirá sendo um dos mais fortes, senão o mais forte, do sistema partidário gaúcho.

\section{Notas}

1 HOHLFELDT, Antônio; MARTINO, Luiz C.; FRANÇA, Vera Veiga. (orgs.). Teorias da Comunicação. Editora Vozes. Petrópolis, 2001.

2 RIMMER, Tony; HOWARD, Mark. Pluralistic ignorance and the spiral of silence: a test of the roles on the mass midia in the spiral of silence hypothesis, in: Mass Comunication Rewiew, 1990, vol. 17, n. 1 e 2.

3 HOHLFELDT, Antônio; MARTINO, Luiz C.; FRANÇA, Vera Veiga. (orgs.). Teorias da Comunicação. Editora Vozes. Petrópolis, 2001, p. 222.

4 SINGLETARY, MichaelW W STONE, Gerald. Communication theory \& Research application. Apud Id.; Ibid., p. 229.

5 NOELLE-NEUMANN, Elisabeth. La espiral del silencio o Opinión Pública: nuestra piel social. Ed. Paidós . México : 1995, p. 118.

6 HOHLFELDT, Antônio; MARTINO, Luiz C.; FRANÇA, Vera Veiga. (orgs.). Teorias da Comunicação. Editora Vozes. Petrópolis, 2001, p. 229.

7 Id.; Ibid., p. 229.

8 Id.; Ibid., p. 230-231.

9 LUHMANN,Niklas.Politischeplanung.AufsätzezurSociologie von Politik und Verwaltung, Opladen,Westdeutscher Verlag, 1971, p. 9-34, apud Elisabeth Noelle-Neuman, Return to the concept of powerful mass midia, op. cit., p. 92, apud ld.: Ibid, p. 232.

10 BRYCE, James. The american commonwealth. Nova lorque, 1924, vol. 1 e 2, apud Id.; Ibid., p. 232.

11 Ver DUVERGER, Maurice. Os partidos políticos. Zahar Editores. Rio de Janeiro : 1970.

12 MOURA, Paulo G. M. de. Como o PT e o Plano Real derrotaram Lula nas eleições presidenciais de 1994. Dissertação de Mestrado. PPG Ciência Política UFRGS. Porto Álegre : 1998.
13 RODRIGUES, Leôncio Martins. Partidos e Sindicatos. São Paulo : Ed. Ática, 1990.

14 CÉSAR, Benedito Tadeu. Verso, Reverso, Transverso - 0 PT e a Democracia no Brasil. São Paulo, 1995, Tese de Doutorado : UNICAMP, 1995.

15 Ver MOURA, Paulo G. M. de. PT: Comunismo ou Socialdemocracia? Ed. Soles. Porto Alegre : 2001. p. 29-30.

16 Id.; Ibid., p. 31.

17 Princípio organizativo adotado pelo Partido Bolchevique russo e seus seguidores, segundo o qual, sob o pretexto de preservar a imagem externa de unidade política e demonstrar força e união perante adversários, os militantes partidários são proibidos de manifestar em público posições divergentes da linha oficial do partido, sendo-lhes reservado, em tese, o direito de questionar essas diretrizes oficiais apenas nas instâncias internas à organização. Na prática, o princípio do centralismo democrático revelouse uma forma antidemocrática de controle da direção sobre a base dos partidos de inspiração marxistaleninista. Segundo definiu Rosa Luxemburgo, que divergia de Lênin em relação à aplicação desse princípio, o centralismo democrático é uma forma de impor a ditadura do Comitê Central sobre o partido, do Birô Político (direção executiva) sobre o Comitê Central, e finalmente, do Secretário Geral (cargo mais importante na hierarquia dos partidos leninistas) sobre o Birô Políico.

18 A política pragmática de alianças que o grupo de Lula (hoje majoritário em nível nacional) patrocina na eleição presidencial de 2002, coligando-se com o Partido Liberal e buscando compor-se regionalmente com inimigos históricos do passado, como Orestes Quércia e Luis Antônio Medeiros em São Paulo, Itamar Franco e José Alencar em Minas Gerais, entre outros casos, não elimina esta constatação, visto que grupos ortodoxos da esquerda petista combatem internamente esse tipo de política de aliança, reafirmando a possibilidade de o PT vencer eleições sem precisar recorrer a esse tipo de iniciativa. No Rio Grande do Sul, notadamente, 0 ex prefeito de Porto Alegre, Raul Pont, expoente da tendência trotskista Democracia Socialista (DS), defende abertamente esse ponto de vista.

19 Ver MOURA, Paulo G. M. de. PT: Comunismo ou Socialdemocracia? Ed. Soles. Porto Alegre : 2001. p. $31-33$ e nota de rodapé 18. 
20 Antônio Gramsci foi um dos principais ideólogos do Partido Comunista Italiano, e formulador de uma concepção estratégica de tomada do poder a partir do conceito de hegemonia.

21 A interpretação da teoria da Hegemonia de Gramsci aqui sintetizada foi extraída de: BOBBIO, Norberto; MATTEUCCI, Nicola; PASQUINO, Gianfranco. Dicionário de Política. Ed. UNB. Brasília : 1992. V. 1, p. 579-581.

22 Apud HOHLFELDT, Antônio; MARTINO, Luiz C.; FRANÇA, Vera Veiga. (orgs.). Teorias da Comunicação. Editora Vozes. Petrópolis, 2001, p. 233.

23 ARRIBAS, Candido Monzon. Origines y primeras teorías sobre opinión pública: El liberalismo y el marxismo. Revista de Estudos Sociais. Mar./Abr. 1985 - Centro de Estudos Contemporâneos. Madrid.

24 HABERMAS. J. Historia y crítica de la opinión pública. Gustavo Gilli, Barcelona, 1981, p. 129-130. apud ld.; Ibid., p. 85.

25 Id.; Ibid., p. 86-88.

26 H. Béjar, Rousseau: opinión pública y voluntad general. In REIS, no 18, abr.-jun. De 1982, p. 75, apud Id. Ibid., p. 88

27 Id.; Ibid., p. 89.

28 HABERMAS. J. Historia y crítica de la opinión pública. Gustavo Gilli, Barcelona, 1981, p. 129-130. apud Id.; Ibid., p. 91.

29 DUVERGER, M. Instituiciones políticas y Derecho constitucional. Ariel. Barcelona, 1980, p. 196, apud 29 Id.; Ibid., p. 92.

30 Id.; Ibid., p. 93.

31 Id.; Ibid., p. 97.

32 Id.; Ibid., p. 97.

33 Id.; Ibid., p. 98-100.

34 Id.; Ibid., p. 100.

35 ld.; Ibid., p. 108.

36 BOURDIEU, Pierre. A opinião pública não existe. In Crítica Metodológica, Investigação Social e enquete operária. Ed. Pólis. São Paulo : 1987. p. 137-151.
37 CHAMPAGNE, Patrick. Formar a opinião - 0 novo jogo político. Ed. Vozes. Petrópolis : 1988.

38 ELIAS, Norbert. La dynamic de l'occident. Calmann-Lévy. Paris : 1975. In CHAMPAGNE, Patrick. Formar a opinião - O novo jogo político. Ed. Vozes. Petrópolis : 1988. p. 21.

39 CHAMPAGNE, Patrick. Formar a opinião - 0 novo jogo político. Ed. Vozes. Petrópolis : 1988, p. 25.

40 Id.; Ibid., p. 25.

41 Id.; Ibid., p. 32.

42 GAXIE. D. Le cens caché. Inégalités culturelles et ségreation politique. Ed. Du Soleil. Paris : 1978 ; e SOFRES. Opinion publique 1984. Gallimard. Paris : 1984, apud Id.; Ibid., p. 35.

43 Id.; Ibid., p. 36.

\section{Referências}

BÉJAR, Helena. Rousseau: opinión pública y voluntad general. In Revista Española de Investigaciones, nº 18, abr.jun. De 1982.

BOBBIO, Norberto; MATTEUCCI, Nicola; PASQUINO, Gianfranco. Dicionário de Política. Brasilia: Ed. UNB, 1992.

BOURDIEU, Pierre. A opinião pública não existe. In: Crítica Metodológica, Investigação Social e enquete operária. São Paulo: Ed. Pólis. , 1987.

BRYCE, James. The american commonwealth. Nova lorque, 1924, vol. 1 e 2.

CÉSAR, Benedito Tadeu. Verso, Reverso, Transverso - 0 PT e a Democracia no Brasil. São Paulo, 1995. Tese de Doutorado: UNICAMP, 1995.

CHAMPAGNE, Patrick. Formar a opinião - 0 novo jogo político. Petrópolis: Ed. Vozes, 1988.

DUVERGER, Maurice. Os partidos políticos. Rio de Janeiro: Zahar Editores, 1970.

DUVERGER, Maurice. Instituiciones políticas y Derecho constitucional. Barcelona: Ariel, 1980.

ELIAS, Norbert. La dynamic de l'occident. Calmann-Lévy. Paris: 1975. In CHAMPAGNE, Patrick. Formar a opinião - 0 novo jogo político. Petrópolis: Ed. Vozes, 1988. 
GAXIE. Daniel. Le cens caché. Inégalités culturelles et ségrégation politique. Paris: Ed. DuSoleil, 1978 ; e SOFRES. Opinion publique 1984. Gallimard. Paris : 1984.

HABERMAS. Jurgen. Historia y crítica de la opinión pública. Barcelona: Gustavo Gilli, 1981.

HOHLFELDT, Antonio; MARTINO, Luiz C:; FRANÇA, Vera Veiga. (orgs.). Teorias da Comunicação. Petrópolis: Editora Vozes, 2001.

LUHMANN, Niklas. Politische planung. Aufsätze zur Sociologie von Politik und Verwaltung, Opladen, Westdeutscher Verlag, 1971, p. 9-34, apud Elisabeth Noelle-Neuman, Return to the concept of powerful mass midia.

MOURA, Paulo G. M. de. Como o PT e o Plano Real derrotaram Lula nas eleições presidenciais de 1994. Dissertação de Mestrado. PPG Ciência Política, UFRGS. Porto Alegre : 1998.

NOELLE-NEUMANN, Elisabeth. La espiral del silencio o Opinión Pública: nuestra piel social. Ed. Paidós . México : 1995.

RIMMER, Tony; HOWARD, Mark. Pluralistic ignorance and the spiral of silence: a test of the roles on the mass midia in the spiral of silence hypothesis. In: Mass Comunication Rewiew, 1990, vol. 17, n. 1 e2.

RODRIGUES, Leôncio Martins. Partidos e Sindicatos. São Paulo: Ed. Ática, 1990.

SINGLETARY, Michael W \& STONE, Gerald. Communication theory \& Research application. 